\title{
القيادة المدرسية الفعالة: مدخلا لتحسين نواتج التعلم بمدارس مملكة البحرين
}

\section{أد/ محمد عبد الرازق ويح}

أستاذ بكلية التربية جامعة بنها - خبير مراجعة أداء المدارس الحكومية والخاصة

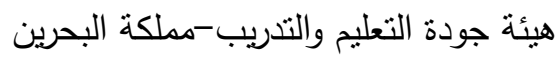

\section{مقدمة}

منذ بدايات القرن الحادي والعشرين بدأت نظهر العديد من التطورات المتسارعة والمتلاحقة نتيجة الأنفجار المعرفي، وثورة المعلومات والاتصالات، والتي أحدثت تحولات وتغيرات عديدة في شتى مناحي الحياة الأنسأنية لاسيّما في مجال الأعمال، والتجارة، وادارة المؤسسات، وقد أحدثت هذه التطورات المتلاحقة، وما زالت تحدث تغييرات كثيرة في إدارة المؤسسات بوجه عام والمؤسسات التعليمية، والتربوية بوجه خاص.

أن التطورات المتسارعة التي تواجهها المؤسسات التربوية في هذا العصر، نتكل بمجموعها تحديات للقيادة التربوية في اختيار الأنماط القيادية المناسبة، للقيام بالمهام التعلمية- التعليمية المطلوبة على أكمل وجه؛ إذ أن النمط المتمركز حول المدير أو اقتصار الإدارة على أفراد محددين لم يعد مناسبا لتسبير العمل الإداري بالمدرسة، بما يتتاسب والتطوير السريع في ميادين المعرفة المختلفة، وهذا يتطلب البحث عن أنماط أخرى جديدة متطورة تتتاسب وطبيعة هذا العصر ، لتحقيق كفاءة عالية من الأداء. وتعد القيادة الفعالة من الأسس الهامة التي تسهم في تحسين أداء المدارس وقيادة عمليات التغيير والتطوير في الميدأن التربوي، وبالنظر إلى التحولات الحديثة التي نشهدها اليوم في ظل العولمة والتحديات الكثيرة التي تفرضها مجتمعات المعرفة، تبرز الحاجة الى تبني أنماطا مغايرة من التفكير، والمعتقدات والسلوكيات التي تساعد القائمين على العمل التربوي على إحداث تطورات جذرية، خاصة في مجال تحسين مخرجات التعلم، ايمأنا بأن محور العملية التعليمية هو الطالب ( مجيد ، 11 • ب). ويعد القائد التربوي أهم عنصر ذي تأثير في أي مدرسة... فقيادته هي التي تحدد نوعية التربية في المدرسة، وطبيعة مناخ التعلم، ومسنوى مهنية المعلمين ونوعية أخلاقهم ودرجة اهتمامهم بالطلاب.... فإذا كأنت المدرسة تقليدية، وذات شخصية غير واضحة، وغير مبتكرة، ودرجة تركيزها متدنية واهتماهها

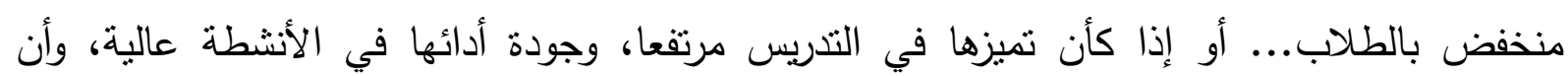
الطلاب يقدمون أفضل ما لديهح من إمكأنات، فأن الأصسابع تتجه إلى قيادة المدرسة كمفتاح للنجاح أو للفثل (آل سليمأن والحبيب، V V • r). 
وعلى المستوى المدرسي تسعى القيادة المدرسية الفعالة إلى تحقيق أهداف المدرسة، من خلال تطوير نظمها وعملياتها، لغرض الاهنمام بجودة التعليم بدلا من الاهتمام بمجرد سير العملية التعليمية، وهذا أدى الهى إلى أن تبرز موضوعات مثل تطوير الأداء القائم على أصول التفكير العلمي والتحليل الموضوعي هني المنظم، الذي بدوره يساعد إدارة المدرسة على تحقيق النمو المرجو منها، حيث يتوقف نجاح الإدارة المدرسية في تحقيق أهدافها بكفاءة وفعالية، على نمط القيادة التي تُعدّ من أهم عناصرها، بل تُعدّ الركيزة الأولى في العملية الإدارية. ومن هنا فقد اتجهت وزارة التربية الى تبني عدة مبادرات تطويرية لتطوير التعليم والتدريب، والارتقاء بمخرجاته، سعيا منها الى تحقيق رؤية المملكة .ب •r. وتتمثل هذه المبادرات في الآتي ( وزارة التربية

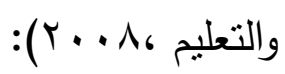

\section{ـ ـ مشروع تحسين أداء المدارس}

أنبثق برنامج تحسين أداء المدارس؛ بهدف دعم المدارس ومساعدتها على التحسن والتطوير من خلال تقديم استنارات خارجية وفحص موضوعي للمجالات التالية:

$$
\begin{aligned}
& \text { الأنجاز الأكاديمي } \\
& \text { التطور الثخصي للطلبة } \\
& \text { التعليم والتعلم } \\
& \text { المنهج الدراسي } \\
& \text { الدعم والتوجيه والمسأندة } \\
& \text { القيادة والإدارة } \\
& \text { القدرة على التحسن } \\
& \text { الفاعلية العامة للمدرسة }
\end{aligned}
$$

وباشرت وحدة مراجعة أداء المدارس عملية المراجعة الأولى في شهر أكتوبر عام ^ ... ب، بعد فترة من العمل التجريبي المكثف الذي شمل حوالي(••) مدرسة حكومية في الفترة ما بين شهر مايو V . . r ومايو 1 . . r، وقد تبين منها أن هناك حاجة ماسة لتحسين أداء المدارس. لذا جاء تدشين برنامج تحسين أداء المدارس على غرار تقييم هيئة جودة التعليم والتدريب في الحادي عشر من نوفمبر عام ^ ... ب، والذي يتكون من: 


$$
\begin{aligned}
& \text { التدريس من اجل التعلم } \\
& \text { القيادة من اجل النواتج } \\
& \text { السلوك من اجل التعلم } \\
& \text { نظام إدارة الأداء }
\end{aligned}
$$

استراتيجية الثقافة العددية، واستراتيجية المهارات القرائية

وتتنتمل خطة تحسين أداء المدارس على العديد من المبادرات الوطنية وبرامج الإصلاح التي تعمل

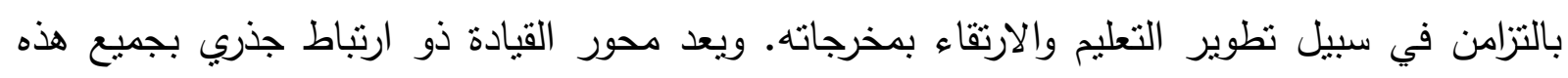
المبادرات سواء على مستوى الإدارات الددرسية، أو ألأفراد الذين يمارسون الأنشطة القيادية في وظائفهر. ولقد تم نطوير نموذج القيادة أنطلاقا من دراسة واقع القيادة المدرسية في مملكة البحرين، والتي أثنارت الى ما يواجه القيادات من تحديات قد تعوق أدائهم في المدارس لقيادة التغيير كمدخل لعملية إصلاح

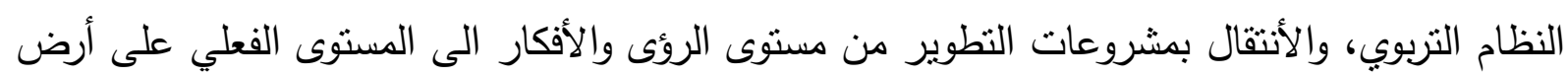

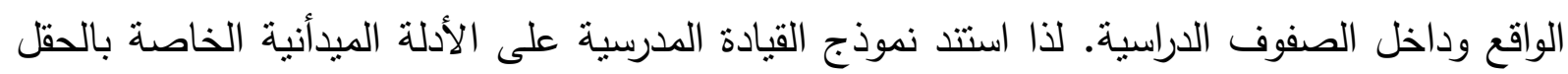

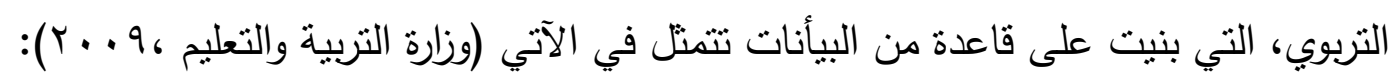
ا ـ التغذية الراجعة والتوصيات الخاصة بالمؤتمرات السنوية لوزارة التربية. r. توصيات نقارير هيئة جودة التعليم والتدريب

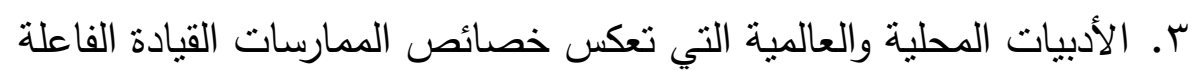
ع. اسنطلاع الرأي الذي قام بها فريق القيادة من أجل النواتج مع الأطراف المعنية في الحقل التربوي.

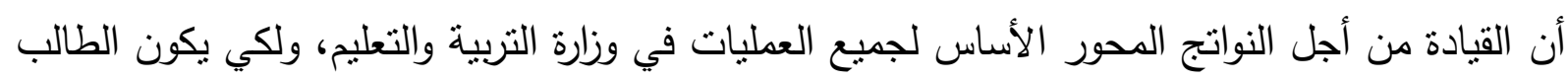
هو محور عملية التعلم، فأن ذلك بتطلب التفكير في القادة كمتعلمين وباحثين، وذوي أداء قيادي فعال وكفاءة عالية؛ لذا يعد نموذج القيادة الفاعل بمثابة خارطة طريق لتحقيق الأهداف المستقبلية. 
القيادة المدرسية الفعالة: مدخلا لتحسين نواتج التعلم بمدارس مملكة

باستعراض الأدبيات في مجال القيادة المدرسية، تبين أن هناك نماذج عديدة للقيادة المدرسية الفعالة، إلا أن ورقة العمل الحالية تبنت نموذجين فقط منها وهما:

Hallinger,2011 أولا: نموذج هالنجر يتضمن نموذج هالنجر ثلاثة أبعاد رئيسة تثمتل في الاتي: البعد الأول: التعريف برسالة الددرسة. البعد الثأني: إدارة البرنامج التعليمي البعد الثالث: تعزيز المناخ التعلمي المدرسي الإيجابي. وبيين ذلك الثكل رقم ( )

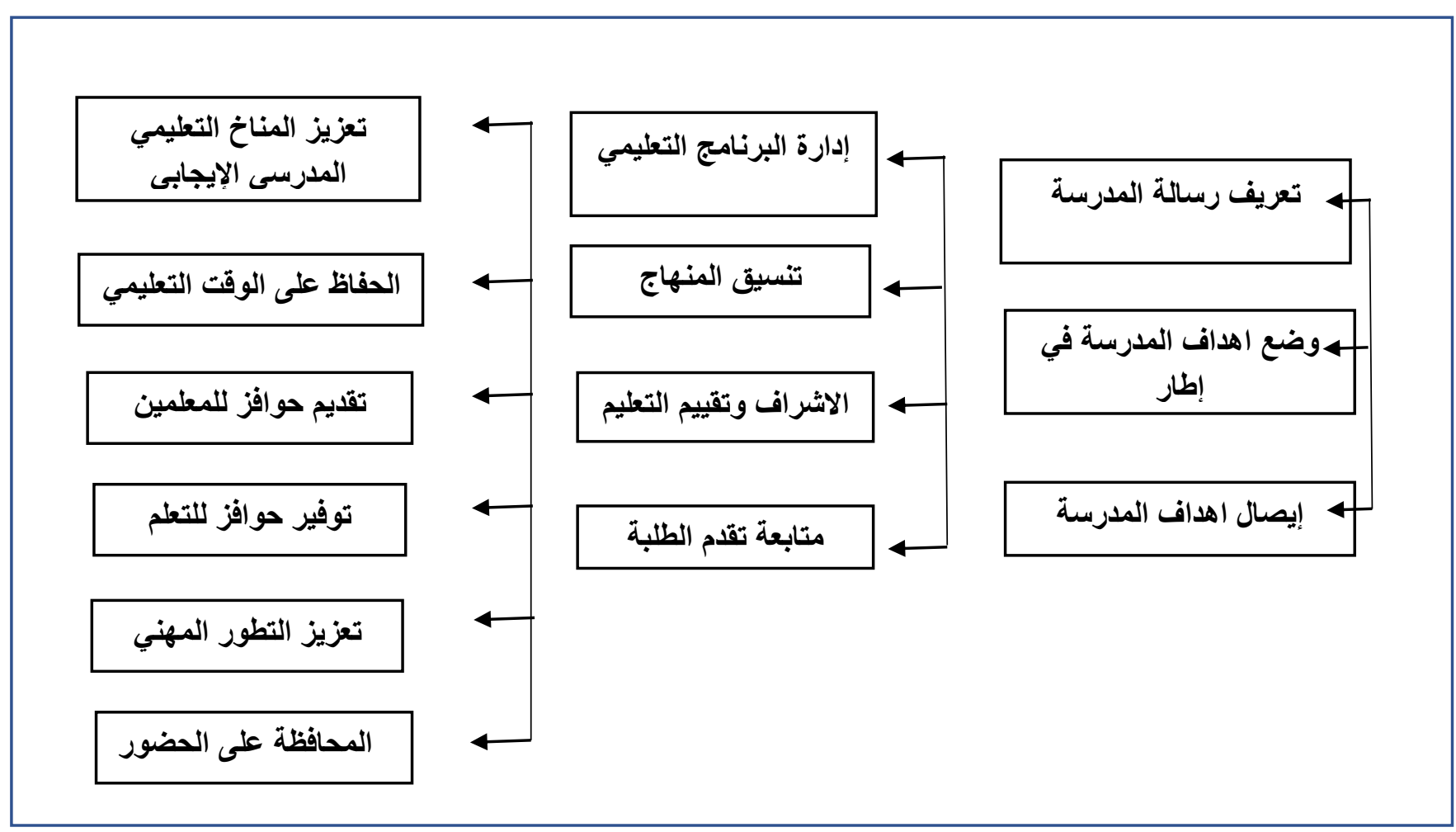

من الثكل السابق لنموذج هالنجر يمكن القول أن الأبعاد الثناثة للقيادة التعليمية لا تفترض أن مدير

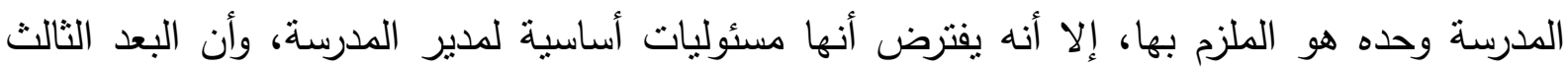
المتعلق بتعزيز المناخ التعلمي المدرسي الإيجابي ينداخل مع الابعاد المندرجة في إطار القيادة التحويلية كما يتضح أيضا أن لمدير المدرسة تأثيرا مباشرا وغير مباشر على سلوك الطلبة وتحصيلهم الدراسي والذي يبينه الثكل رقم(ץ ) وذلك على أساسا الربط بين سياسات المدير وسلوكياته وممارساته 
القيادة المدرسية الفعالة: مدخلا لتحسين نواتج التعلم بمدارس مملكة

المجلة العربية للقياس والتقويم

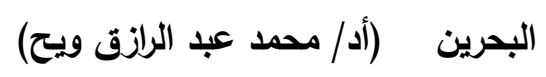

\begin{tabular}{|c|c|c|}
\hline اتجاهات وسلوك & اتجاهات وسلوك & سياسات وممارسات \\
\hline تحصيل & المعلمون & تعريف رسالة \\
\hline تحصيل & المعلمون & 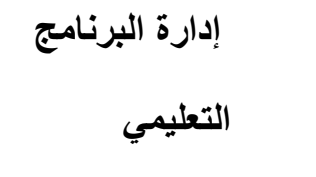 \\
\hline تحصيل & المعلمون & تعزيز المناخ \\
\hline
\end{tabular}

نموذج القيادة التريوية في مدارس مملكة البحرين

يتكون نموذج القيادة التربوية في مدارس مملكة البحرين الحكومية من خمسة عناصر أساسية، مترابطة فيما بينها، وتم تدريب جميع مديري المدارس وكذا المدراء المساعدين على تطبيق هذا النموذج، والذي اضحى بدوره ثقافة متجذرة في الغالبية العظمى من المدارس الحكومية. وفيما يلي عرض لعنصر هذا النموذج ( وزارة التربية والتعليم، 9 . . ؟): 


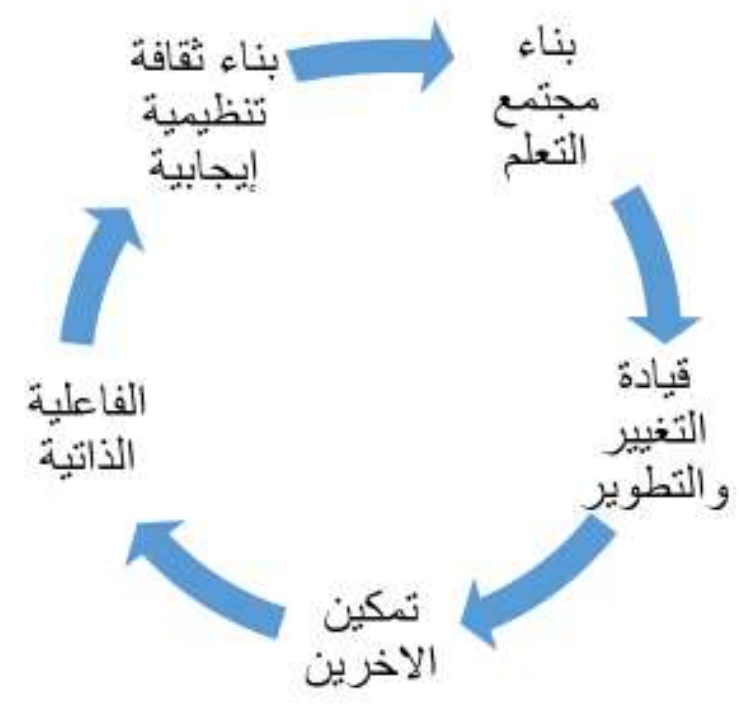

أولا: بناء مجتمع التعلم

أن بناء مجتمع التعلم من أهم الأدوار التي ينبغي أن يقوم بها القائد في المؤسسة التعليمية، ويمكن تحقيق ذللك من خلال الممارسات التالية:

ا. التركيز في التعلم، وجعله محورا أساسيا في التخطيط الاستراتيجي للمدرسة، ويتمثل ذلك في أن:

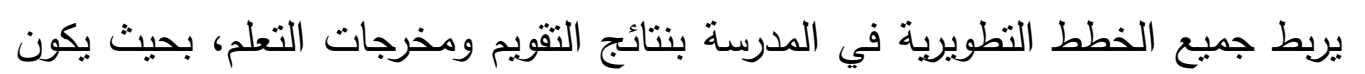
التعليم والتعلم من أهم أولوياته عند اعداد الخطة الاستراتيجية للمدرسة. بيرز أهمية التعليم والتعلم في رؤية المدرسة وأهدافها. يضع برامج عمل محددة واضحة تستتد الى استراتيجيات تعلم متتوعة للارتقاء بعمليات التعليم والتعلم.

r. مشاركة جميع الأطراف في العملية التعليمية التعلمية، ويتمثل ذلك في أن: • يعمل على مشاركة جميع العناصر الأساسية في اتخاذ القرارات (الطالب-المعلم-ولي فئي (الامر).

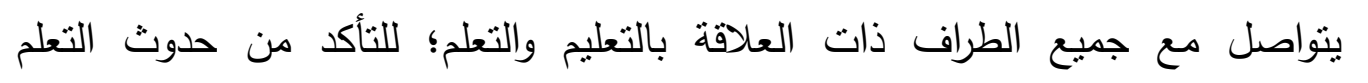

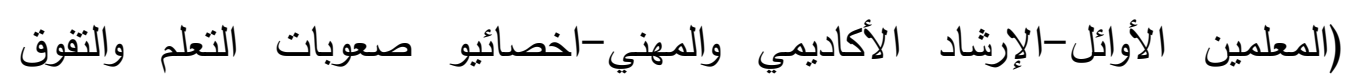
والموهبة).

يفعل دور المجالس المدرسية ويوظفها في العملية التعليمية التعلمية (مجلس الإدارةاللجنة الفنية-مجلس الطلبة-مجلس الآباء) 
يستثر الإمكانات المادية والبشرية في المجتمع المحلي لخدمة العملية التعليمية (المركز

$$
\begin{aligned}
& \text { الصحي -مؤسسات المجتمع المحلي -الجمعيات الاهلية) } \\
& \text { r. متابعة تحصيل الطلبة، ويتمثل ذلك في أن: } \\
& \text { يدرس ويتابع باستمرار نتائج تحصيل الطلبة. }
\end{aligned}
$$

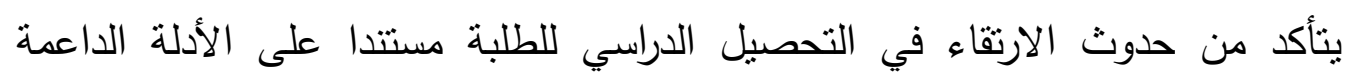

$$
\text { (الإحصائيات-تحليل النتائج) }
$$

يوظف إمكأنات المدرسة لرعاية ودعم الطلبة على اختلاف فئاتهم (المتفوقين -الموهوبين -

$$
\text { ضعاف التحصيل. }
$$

يوظف نتائج الاختبارات الوطنية في إعداد برامج للارتقاء بمستوى الإتقأن لدى الطلبة.

ع. تنمية ثقافة البحث والتفكير الناقد، وينمثل ذلك في أن:

$$
\text { هنمي مهارة استسقاء المعلومات لاى منتسبي المدرسة }
$$

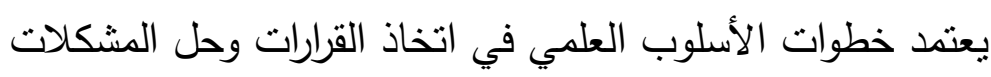

يشجع على تنبني أسلوب التفكير الناقد البناء وتعزيز مبدا احترام الرأي الآخر

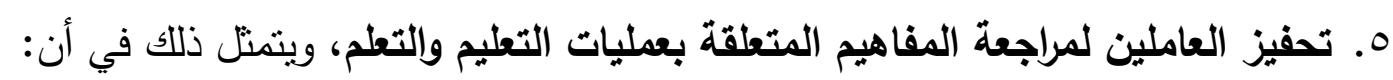
• يحفز منتسبي المدرسة على تبني مفاهيم إيجابية حديثة منطورة حول عمليات التعليم

$$
\text { والتعلم. }
$$

يشجع العاملين على البحث والاطلاع بهدف مواكبة المستجدات التربوية هوظف ما يتميز به المعلم من قدرات لخدمة العملية التنربوية والتعليمية 7. توظيف شبكات وأنظمة تواصل فاعلة، ويتمثل ذلك في أن: يعتمد أنظمة تواصل فاعلة مع الأطراف ذات الصلة بعمليات التعليم والتعلم ( الطالب/ تواصل

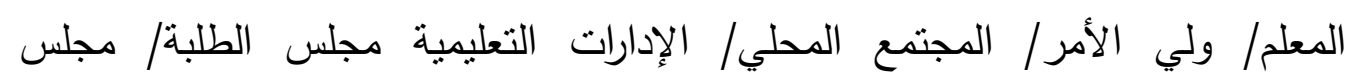
الآباء.....

يوظف آليات التواصل المختلفة للارتقاء بعمليات التعليم والتعلم • ب بستثمر التقنية الحديثة في التواصل بين جميع الطراف المعنية بعمليات التعليم والتعلم V Vتمية العاملين مهنيا، ويتمتل ذلك في أن:

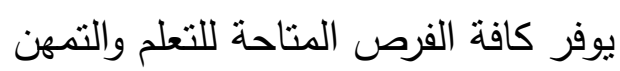
هحد احتياجات ألأفراد من البرامج التنريبية 
القيادة المدرسية الفعالة: مدخلا لتحسين نواتج التعلم بمدارس مملكة

ينوع من أساليب التتمية المهنية (زيارات صفية وتبادلية-ورش عمل-جلسات تطوير -

$$
\begin{aligned}
& \text { زيارات لمدارس.................... } \\
& \text { ثأنيا: قيادة التغيير والتطوير }
\end{aligned}
$$

أن الهدف الأساسي لكل قائد ناجح هو إتقأن المعارف والكفايات والاستراتيجيات الضرورية لإحداث التغيير الإيجابي وتطبيقه بنجاح في مؤسته التعليمية، لذا فأن اطلاع القادة التربويين على أبرز الأفكار

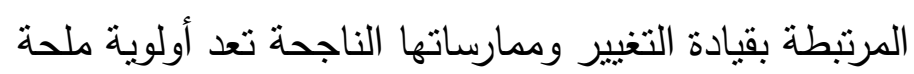
ويمكن للقائد أن يحقق ذلك من خلال الممارسات التالية: ا ـ تبني التغيير والاقتناع بأهميته، ويتمنل ذلك في أن: يستشعر الحاجة الى التغيير من خلال متابعة آخر المستجدات في الميدأن التربوي وخاصة في مجال القيادة يحرص على اقناع منتسبي المدرسة بالتغيير واهيته ويعمل على إثاعة هذه التقافة من خلال اللقاءات والزيارات ونتائج تقويم الإدارة التعليمية وتقارير هيئة جودة النعليم يعمل على تذليل الصعوبات والتغلب عليها r. تهيئة البيئة الملائمة للتغيير، ويتمثل ذلك في أن: يضع استراتيجيات فاعلة لإحداث عملية التغيير وتطبيقها ومتابعة تتفيذها.

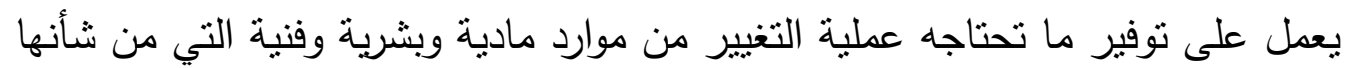
تحقق الأهداف المرجوة يوفر الدعم الإيجابي لكافة أفراد المؤسسة ويتجنب خذلانهم

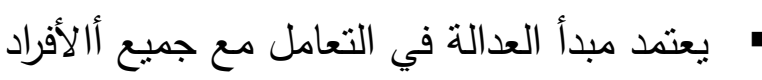
يتبنى أسلوب الحوار البناء ويشارك كافة ألأفراد الدعنيين في اتخاذ القرارات يعمل على إثاعة روح العمل التعاوني بين أفراد المؤسسة التربوية

r. التحفيز على الابداع والابتكار، ويتمنل ذلك في أن: يحترم المبادرات الإبداعية للعاملين معه، ويعمل على تتجيعها من خلال التحفيز المادي والمعنوي 
يسعى لتطوير قدرات العاملين معه لمواكبة متطلبات العصر والتحديث باعتباره عملية

$$
\text { مستمرة }
$$

$$
\begin{aligned}
& \text { • يحفظ حقوق العاملين المعنوية والمادية } \\
& \text { ع. تشجيع التطوير والمبادرات، ويتمنل ذلك في أن: }
\end{aligned}
$$

$$
\text { يتبنى البرامج التطويرية ويدعمها معنويا وماديا }
$$

ييرز المبادرات الإبداعية للعاملين معه بما يخلق بيئة محفزة

يعزز الدافعية للارتقاء بقدرات وأداء العاملين معه لمواجهة المستجدات المتلاحقة

$$
\text { ه. مواجهة التحديات واستثمارها في الارتقاء بالمدرسة، ويتمنل ذلك في أن: }
$$

يعمل على إقناع أعضاء المؤسسة غير الراضين عن عملية التغيير والتطوير وعدم

$$
\text { تجاهلهم تشخص واقع المدرسة بصورة عملية محايدة }
$$

يبني خطط التغيير المدروسة من خلال مشاركة العاملين معه في بناء نظام تربوي جديد

- يستجيب للتحديات الراهنة ويستبق التفكير في المستقبل للارتقاء بالمؤسسة المدرسية

ثالثا: تمكين الآخرين

وتعني قدرة القائد التربوي على إيجاد بيئة مؤسسية تتسم بتوزيع الأدوار والصلاحيات وإشراك ألأفراد في عملية اتخاذ القرارات؛ من أجل تهيئة الفرصة لأفراد المؤسسة التربوية لممارسة أدوار قيادية تتمي لديهر المسئولية والدافعية نحو تحقيق ممارسات تعليمية ناجحة

ويتقق الكثير من الباحثين وعلماء التربية والإدارة بأن قائد المدرسة يعتبر عنصرا جوهربا ومؤثرا في المؤسسة المدرسية، ويلعب دورا هاما في تحقيق او إيجاد بيئة تعليمية تحقق التتمية المستخامة، كما أن بأن هناك شبه اتفاق بأن القيادة الفعالة شرط أساسي لتحقيق النجاح وتحسين مخرجات التعلم

$$
\text { ا ـ تحفيز الآخرين لبلوغ اعلى مستويات الاداء، ويتمثل ذلك في أن: }
$$

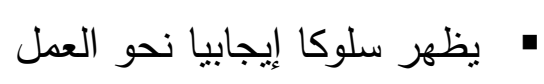

" بحفز أفراد المؤسسة وبيرز ممارساتهم الجيدة

$$
\text { بدعم الابتكارات والإبداعات الفردية }
$$

يضع أهدافا للمرؤوسين تتحدى قدراتهم وتساعد على تطوير أدائهم

$$
\text { r ـ توفير الاعم وتذليل الصعويات، ويتمنل ذلك في أن: }
$$


هسعى إلى توفير الموارد اللازمة لدعم عمليات التعليم والتعلم

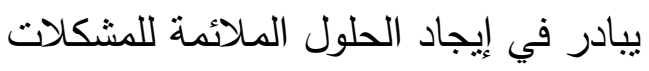

يشارك الأفراد في تذليل الصعوبات التي تعترض العمل

r. تفويض الصلاحيات وتوزيع الأدوار، ويتمثل ذلك في أن:

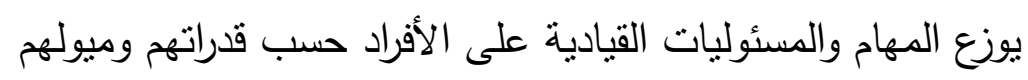

يساند الأفراد ويتيح لهم الفرص للتعلم من التجارب الناجحة

يحترم الفروق الفردية في قدرات المرؤوسين

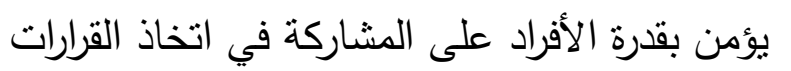

ع. تعزيز الممارسات الجيدة، ويتمنل ذلك في أن:

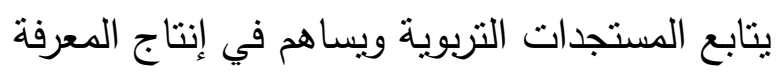

يحث الأفراد على القراءة والاطلاع والمناقثات المتعلقة بالممارسات الجيدة لهنداته

يتواصل مع المؤسسات المعرفية لتعزيز التتمية المستدامة

ه. توفير المناخ التربوي لتهيئة قيادات جديدة، ويتمنل ذلك في أن:

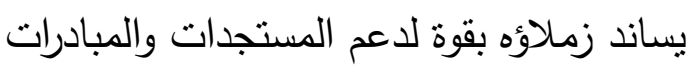

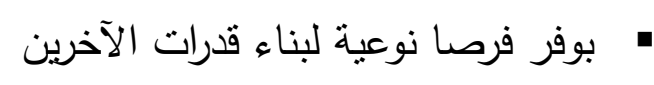

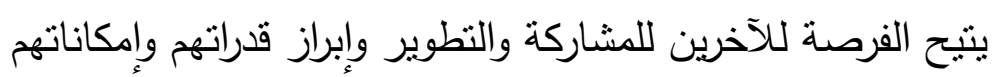

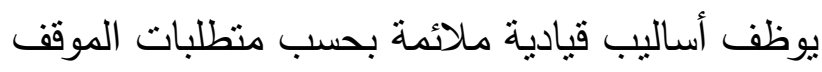

$$
\text { هيرز القدرات الناجحة للأفراد }
$$

1. تعزيز روح التعاون والعمل الجماعي، ويتمنل ذلك في أن:

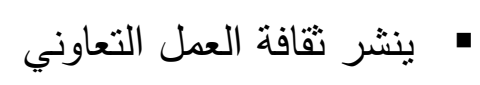

• بشجع التعاون البناء بين العاملين بما يحقق اذكاء روح العمل الجماعي بينهم

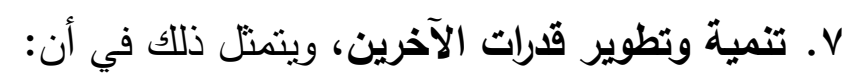

$$
\text { يؤمن بقدرات الأفراد على التعلم }
$$

• يخطط للتمية المهنية ويجعلها من الأولويات لجميع أفراد المؤسسة

يعد قدوة حسنة للآخرين في اغتنام فرص التتمية المهنية

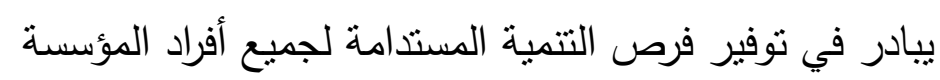




\section{رابعا: بناء ثقافة تنظيمية إيجابية:}

لكل مدرسة ثقافتها الخاصة التي تميزها عن غيرها من المدارس، وتتكون هذه الثقافة من القيم والمعتقدات والعادات والتقاليد والمبادئ والتوجهات التي يكونها الأفراد وتؤثر بهم ومن ثم تحدد وتوجه سلوكهم.

إن وجود ثقافة تتظيمية يعد أمرا في غاية الأهمية، إذ تكمن أهمية الثقافة التتظيمية في أنها تعمل على تزويد الفرد بالقدرة على الفهم ومن ثم التكيف والتعامل مع المعطيات والمؤثرات الداخلية والخارجية، وبيرز دور قائد المدرسة في بناء وتتمية ثقافة تتظيمية إيجابية من خلال الأدوار والممارسات التي يقوم بها وتعزبز المناخ الصحي الذي يعمل على تفعيل هذه الثقافة

ويمكن لمدير المدرسة أن يحقق ذلك من خلال الممارسات التالية:

ا ـ تنمية روح الانتماء والولاء للمدرسة، ويتمنل ذلك في أن:

$$
\text { • يؤكد وبيرز أهمية كل فرد في المدرسة }
$$

يصنف الوظائف المتاحة في مدرسته ويوفر لكل وظيفة الوصف الوظيفي للمهام المنوط

بها كل موظف

يوضح قواعد المساءلة والتحفيز المتعلقة بهذه المهام

يراعي حقوق الموظف وبؤكد على واجباته وحقه في التتمية المهنية والثخصية

يقوم بحصر الاحتياجات التدريبية لكل منتسبي مدرسته

يبدا بتتفيذ البرامج التدريبية حسب الأولويات وظروف مدرسته

يحدد آلية لتقويم التدريب وطريقة لقياس أثز هذا التدريب

r. العمل على بناء روئية مشتركة ويتمثل ذلك في أن:

يدعم استقرار مدرسته من خلال العمل المشترك بين أفرادها

يصنف قدرات منتسبي مدرسته حسب قدراتهم ويحتفظ بها في قاعدة بيانات.

•حدد برامجه التي تحقق أولوياته وأهدافه وفي إطار تعاوني لإظهار قدرات منتسبي

مدرسته

يوضح لكل منتسبي مدرسته أهمية الرؤية المستقبلية لها

يشرك معظم منتسبي مدرسته في بناء وصبغة رؤيتها

يشرك العاملين في تقييم وضع مؤسستهم الراهن وتحديد الأولويات للتعاون على تحقيقها

يوضح الأهداف العامة والخاصة لكل منتسبي مدرسته لتحقيق رؤية المدرسة ورسالتها. 


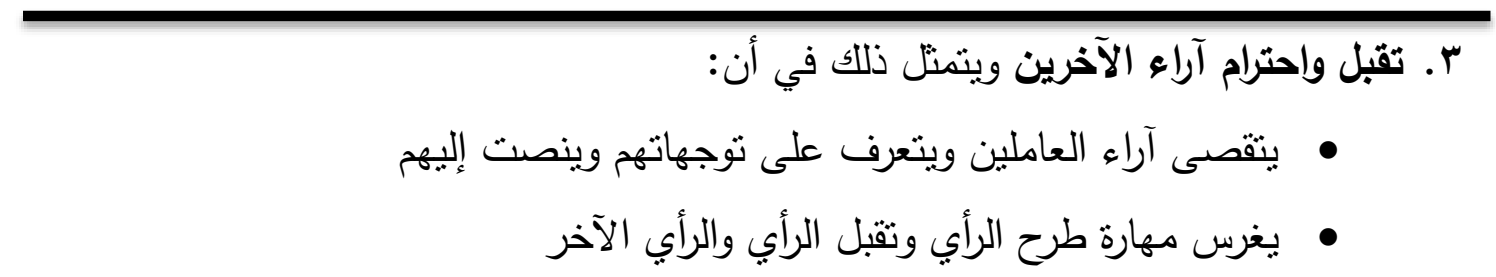

هشرك الجميع في عمل المدرسة ويستشيرهم ويتقبل الأفكار والمقترحات البناءة التي

\section{يقدمونها}

\section{ع. توفير جو من الالفة والمودة ويتمثل ذلك في أن:}

هشيع جوا من الألفة والمودة والعلاقات الإنسانية التي تساعد على الالتزام بين العاملين

يخطط للارتقاء بمهارات العلاقات بين أفراد مؤسسته التعليمية

يعقد الحلقات النقاشية في العلاقات المختلفة في سياق عمل تعاوني

يدعم العلاقات التعاونية وروح المشاركة بين أفراد مدرسته

• يشجع الأفكار البناءة في تأصيل روح التعاون ومبادئه

هـ تعزيز القيم والمعتقدات الإيجابية والبناء عليها ويتمثل ذلك في أن:

يوفر الدعم والمساندة للقيم الإيجابية التي تؤمن بها المدرسة

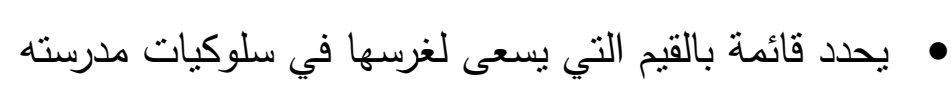

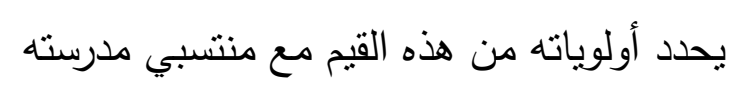

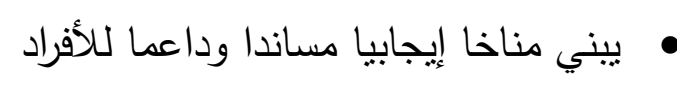

•يقدم الحوافز لمستحقبها ويتنىى الثفافية في تطبيقها ويوضح أسسها وقواعدها.

\section{خامسا: الفاعلية الأتية}

هي مجموعة المعتقدات التي يحملها الفرد عن نفسه فيما يتعلق بقدراته على تعلم او أداء سلوك محدد عند مستوى معين، وتلعب الفاعلية الذاتية دورا هاما في أن يكون الفرد إيجابيا يجدد قدراته باستمرار ويقدم الأهم على المهم ويفكر في المنفعة المشتركة لجميع الأطراف

ويمكن للقائد أن بحقق ذلك من خلال الممارسات التالية:

ا ـ تحمل المسئولية باقتدار ويتمنل ذلك في أن:

هؤدي مسئولياته على أكمل وجه دون تقصير أو تأخير ويحظى بالتقة من مرؤوسيه

بطور قدراته على اتخاذ القرارات بالاستتاد الى الحقائق والبيانات 


\section{يتصرف باتزان وهدوء، وبعيدا عن الانفعالات

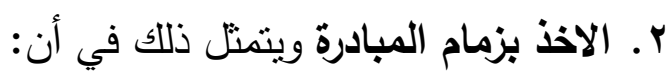

بطرح الرؤى ويقدم المقترحات والآراء الجديدة ويساهم في النطوير البناء

يتحرر من قيود العمل الروتيني ولديه الجرأة على تبني المشروعات الجديدة

هيادر باكتثاف المشاكل والثغرات عن طريق استثمار ما يمنلك من معلومات وتقارير

$$
\text { r. تظوير الذات ويتمنل ذلك في أن: باكن }
$$

• يراجع عمله ويسعى لتطويره من خلال التوظيف الفعال لمؤشرات الجودة

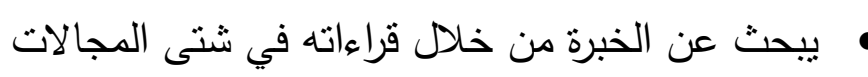

بستقيد من الأفكار المبتكرة ويضيف عليها وينميها

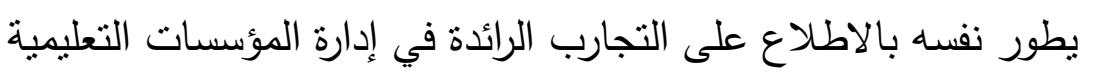

ع. قدوة ونموذج للآخرين ويتمثل ذلك في أن:

يلتزم بالمواعيد ومنضبط

يقوم بالعمل قبل أن يطلب منلك من زملائه ومن مرؤوسيه

يتفانى في العمل ويتحمل المسئولية

بتمتع بروح المبادرة

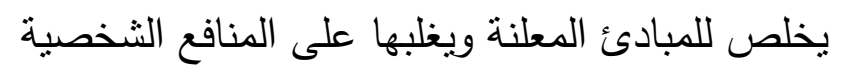

هـ إيجابي ينظر بأمل وتفاؤل ويتمثل ذلك في أن:

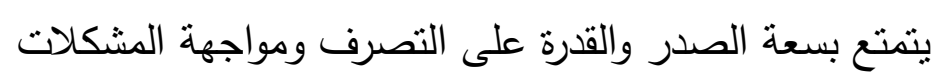

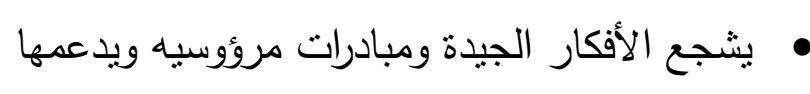

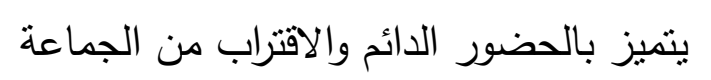

7. منصت جيا ويتنتل ذلك في أن:

هيتمع للآخرين بتمعن في أقوالهم ويتفاعل معهم مما بساعد على تدفق المعلومات

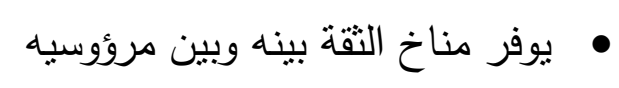

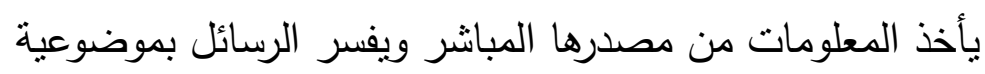

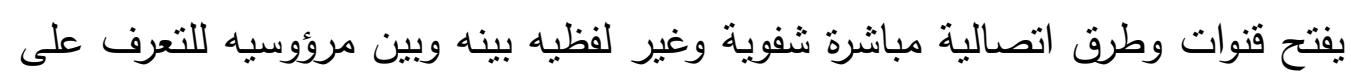

وجهة نظر الطرف الثاني وفهمه

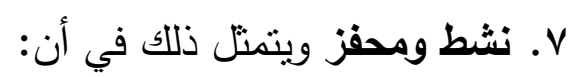


يعزز الممارسات الجيدة في المجتمع المدرسي ويشيع الحيوية والنشاط في مرؤوسيه

هقدم الى مرؤوسيه الدعم الذي يحتاجونه ويشجعه ويثتي عليهم ويمدحم بشكل يساعد

$$
\text { على رفع معنوباتهم }
$$

يناقش أعمال مرؤوسيه بصورة مستمرة وبناءة

بدفع العاملين لمزبد من العطاء عن طريق تحفيز المجدين ورفع معايير الأداء

هيتجنب كل ما يثير عزوف الآخرين وعداءهم كالانتقاد اللاذع وغير الموضوعي او عدم

المساواة في التحفيز

^. الثقة بالتفس والقدرات ويتمنل ذلك في أن:

يثث بقدرته على النجاح والاستمرار في المسئولية

يزود رؤسائه ومرؤوسيه بالمعلومات الكافية لتكوين صورة أوضح عن الأهداف المراد

\section{تحقيقها}

9 ـ . يقوم خطواته بشكل منتظم ومستمر ويتمنل ذلك في أن:

• يضع آليات واضحة وخطط تدفقية زمنية للمتابعة

$$
\text { • يُقوم مدى تحقق الأهداف بصورة دورية }
$$

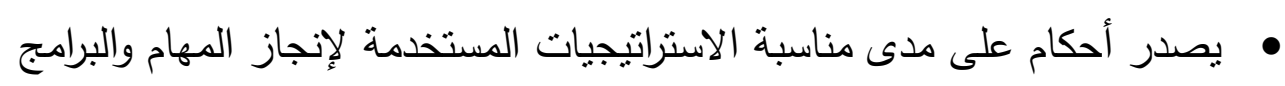

$$
\text { يُقوم نفسه بالاستتاد الى مؤشرات نجاح واضحة. }
$$

ويتفق توبن Toppin,2002 مع نموذج القيادة الددرسة الفعالة في البحرين، حيث أشنار الى أن قائد المدرسة ينبغي أن بمتلك مجموعة من الكفايات التي تمكنه من أداء مهامه بفعالية وتتمثل في:

1 ا ـ تطوير وتتمية العاملين

r. تطوير المؤسسة بتشجيع المبادرة والابتكار

r. إبراز السلوك الأخلاقي

ع. حل المشكلات واتخاذ القرارات

○. بناء الفرق الداخلية والاستفادة منها

7. تفعيل التفكير الاستراتيجي

V. التواصل مع الآخرين

^. الفهم الجيد للظروف الداخلية والخارجية، والروئية والرسالة والاهداف والاستراتيجيات 


\section{انعكاس أثر تطبيق نموذج القيادة التربوية على تحسين نواتج التعلم بمدارس مملكة البحرين}

$$
\text { ا ـ إعداد المدارس خططا استراتيجية بحسب نموذج التخطيط الاستراتيجي. }
$$

r. تركيز مجالات نموذج المدرسة البحرينية المتميزة على التطور الثخصي للطالب وتحصيله الدراسي والتعليم والتعلم والدعم الذي يقدم لله، كما أن مشروع القيادة من أجل النواتج وضع الطالب وتحصيله في نموذج التخطيط الاستراتيجي كأولوية في بناء الخطة الاستراتيجية للمدرسة، وفي مشروع الشراكة من أجل الأداء ركزت مؤشرات الأداء المدرسي على التحصيل الدراسي من خلال( معدل التخرج ومتوسط درجات الاختبارات الوطنية والمدرسية، ومتوسط الربع الأخير لدرجات الاختبارات الوطنية المدرسية للطلبة، وتقويم التعليم والتعلم، والتطور الثخصي للطلبة من خلال نسبة الحوادث السلوكية ومعدل حضور الطلبة، في حين ركز مشروع التدريس من أجل التعلم على المهارات التي يحتاجها المعلمون؛ لتحقيق التحسين في أساليب التعلم لاى الطلاب وكيفية مراعاة الفروق الفردية بين الطلبة وتدريس المهارات العليا من التفكير . r. التحسن الواضح في نسب إتقان الكفايات في المواد الدراسية الأساسية (اللغتين العربية والإنجليزية، والعلوم والرياضيات) في المراحل التعليمية المختلفة خاصة الابتدائية. ـ. تحسن أداء المدارس في مراجعات هيئة جودة التعليم والتدريب، حيث إنه في العام الماضي

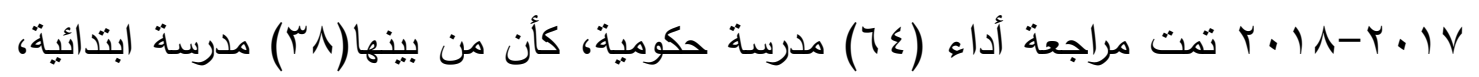

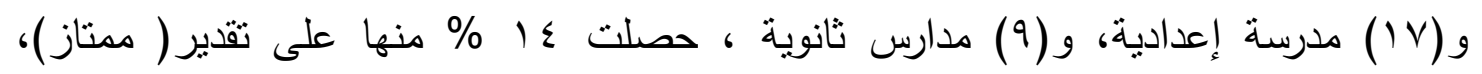

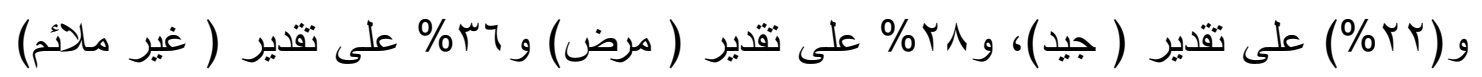
تركزت بصورة كبيرة في المرحلة الإعدادية، ويعزى ضعف أداء تلك المدارس الى تحديات منباينة ترتبط في عمومها بعدم استقرار الهيئتين الإدارية والتعليمية، والذي تتاغم مع ضعف أداء بعض الهيئات التعليمية، إضافة الى تحديات مرتبطة بالطلبة من حيث قدرة المدارس على التعامل معهم كتتوع خلفياتهم الثقافية، ومع الطلبة الذين لغتهم الأم غير العربية وبعض التحديات المرتبطة بسلوك الطلبة ووعيهم ووعي أولياء امورهم( هيئة جودة التعليم والتدريب، 1 ( • ). ه. نشر الممارسات المتميزة كالتقييم الذاتي الدقيق المبني على تشخيص واقع المدرسة الفعلي، وبناء خطط استراتيجية في ضوء الأولويات، وفاعلية برامج التطوير المهني للمعلمين 7. تحسن أداء الطلبة في الامتحانات الوطنية للصف السادس في اللغة العربية واللغة الإنجليزية والعلوم والرياضيات. 
القيادة المدرسية الفعالة: مدخلا لتحسين نواتج التعلم بمدارس مملكة

V. تحسن أداء طلبة الصف الثاني عشر في الامتحانات الوطنية في اللغتين العربية والإنجليزية،

\section{وحل المشكلات}

^. تحسن أداء جودة التعليم البحريني دوليا في مؤشرات التتافسية العالمية لمنتدى دافوس

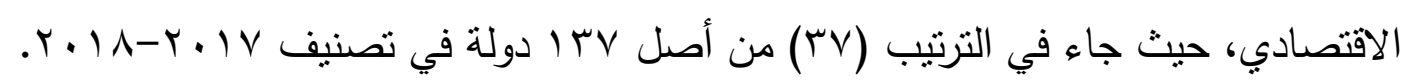

\section{المراجع}

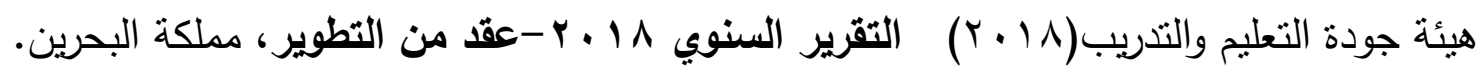
وزارة التربية والتعليم(^ . . ؟) المشاريع التطويرية-تحسين أداء المدارس، مملكة البحرين وزارة التربية والتعليم(9 . . ا) الدليل الاسترشادي للقيادة التريوية، مشروع القيادة من اجل النواتج، مملكة البحرين

آل سليمان، زيد بن ناصر، والحبيب، عبدالرحمن بن محمد(Y V P (متطلبات تطوير أداء القيادات المدرسية في ضوء معايير جودة القيادة المدرسية لهيئة تقويم التعليم بالمملكة العربية السعودية، مجلة كلية التربية الاساسية للعلوم التريوية والإنساتية، جامعة بابل، العدد

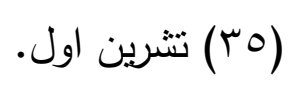


القيادة المدرسية الفعالة: مدخلا لتحسين نواتج التعلم بمدارس مملكة

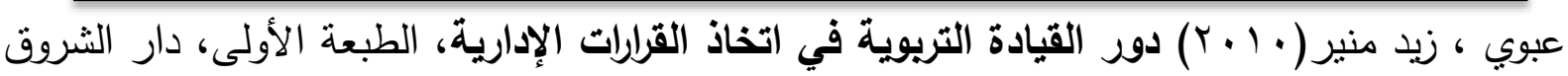
للنشر والتوزيع، عمان

مجيد، سوسن شاكر(1) ( • ب) تقويم جودة الأداء في المؤسسات التعليمية، دار الصفاء للنشر والتوزيع، عمان.

7.Toppin, Peter A. $(Y \ldots Y)$. Managerial Leadership, U.S.A, New York, McGraw-Hill

8. Hallinger, Ph. (2011a). A review of three decades of doctoral studies using the principal instructional management rating scale: A lens on methodological progress in educational leadership. Educational Administration Quarterly, 47(2), 271-306. Retrieved April 6, 2011 from: http://eaq.sagepub.com/content/47/2/271. 